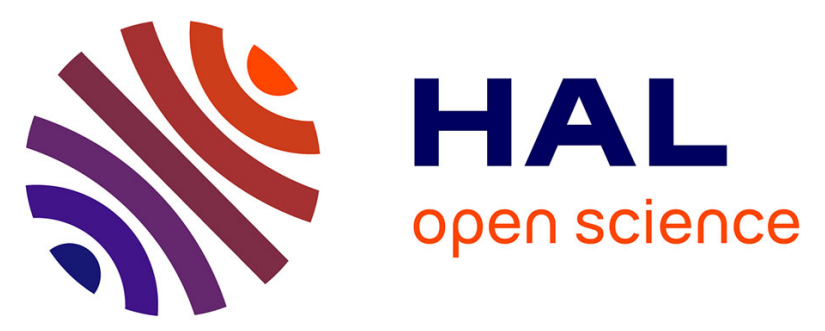

\title{
Formation of Al containing molecular complexes in the gas phase in dense molecular clouds: quantum study of the radiative association of $\mathrm{Al}++\mathrm{H} 2$ and $\mathrm{Al}++\mathrm{D} 2$
}

\author{
Daria Jones , Gunnar Nyman, Thierry Stoecklin
}

\section{- To cite this version:}

Daria Jones , Gunnar Nyman, Thierry Stoecklin. Formation of Al containing molecular complexes in the gas phase in dense molecular clouds: quantum study of the radiative association of $\mathrm{Al}++\mathrm{H} 2$ and Al++D2. Monthly Notices of the Royal Astronomical Society, 2021, 503 (2), pp.3089-3094. 10.1093/mnras/stab697 . hal-03359463

\section{HAL Id: hal-03359463 https://hal.science/hal-03359463}

Submitted on 16 Nov 2021

HAL is a multi-disciplinary open access archive for the deposit and dissemination of scientific research documents, whether they are published or not. The documents may come from teaching and research institutions in France or abroad, or from public or private research centers.
L'archive ouverte pluridisciplinaire HAL, est destinée au dépôt et à la diffusion de documents scientifiques de niveau recherche, publiés ou non, émanant des établissements d'enseignement et de recherche français ou étrangers, des laboratoires publics ou privés. 


\title{
Formation of Al containing molecular complexes in the gas phase in dense molecular clouds: Quantum study of the radiative association of $\mathrm{Al}^{+}+\mathbf{H}_{2}$ and $\mathrm{Al}^{+}+\mathbf{D}_{2}$
}

\author{
Daria Jones (nee Burdakova), ${ }^{1}$ Gunnar Nyman, ${ }^{1}$ Thierry Stoecklin,${ }^{2 \star}$ \\ ${ }^{1}$ Department of Chemistry and Molecular Biology, University of Gothenburg, 41296 Gothenburg, Sweden \\ ${ }^{2}$ Université de Bordeaux, ISM, UMR 5255, 33405, Talence, France
}

Accepted XXX. Received YYY; in original form ZZZ

\begin{abstract}
Radiative association (RA) of $\mathrm{Al}^{+}$with $\mathrm{H}_{2}$ is the first step in the formation of $\mathrm{AlH}$ in gas phase and is here investigated theoretically. We use recent potential energy and dipole moment surfaces and a quantum approach based on the driven equations formalism for performing the dynamics for both the $\mathrm{Al}^{+}-\mathrm{H}_{2}$ and $\mathrm{Al}^{+}-\mathrm{D}_{2}$ systems. The obtained $\mathrm{RA}$ rate coefficients are compared with previous evaluations based on transition state theory and found to be orders of magnitude larger. They are also compared to those obtained recently for the similar systems $\mathrm{Na}^{+}-\mathrm{H}_{2} / \mathrm{D}_{2}$. The possible role played by RA of $\mathrm{Al}^{+}$with $\mathrm{H}_{2}$ in the gas phase chemistry of dense molecular clouds is discussed.
\end{abstract}

Key words: astrochemistry - radiative association- molecular data - molecular processes scattering - ISM: molecules.

\section{INTRODUCTION}

Gas phase reactions involving metals is a relatively new topic in astrochemistry as metals were believed to accumulate on dust grains and seldom participate in gas phase reactions. When several gas phase molecules containing metals $(\mathrm{NaCl}, \mathrm{AlCl}, \mathrm{KCl}, \mathrm{AlNC}, \mathrm{AlO}$, $\mathrm{AlOH}, \mathrm{AlF}, \mathrm{Na}(\mathrm{CN}), \mathrm{MgCN}, \mathrm{MgNC})$ were observed in the envelope of IRC+10216 (Cernicharo \& Guelin (1987), Kawaguchi et al. (1993), Turner et al. (1994), Ziurys et al. (1994), Ziurys et al. (1995), Tenenbaum et al. (2010)) it proved that metals can form molecules in the interstellar medium. AlO has also been found in stellar photospheres, both in absorption and emission via its electronic transitions (Kamínski, T. et al. 2016).

$\mathrm{AlH}$ is one of the simplest hydrogen-metal systems that is yet to be detected. Considering the relatively high abundance of aluminum $\left(3 \times 10^{-6}\right)$ together with the fact that aluminum bonded to a rarer element such as fluorine or chlorine has been detected, the $\mathrm{AlH}$ molecule may be expected to be present as well.

As discussed in a previous paper (Burdakova et al. 2019) dedicated to the formation of $\mathrm{NaH}$, the gas phase mechanism mentioned already by Kirby \& Dalgarno (1978) consists of two steps. The first step, here written for a general atomic metal ion $\mathrm{M}^{+}$, is the radiative association of it with $\mathrm{H}_{2}$ :

$\mathrm{M}^{+}+\mathrm{H}_{2} \rightarrow \mathrm{M}^{+}-\mathrm{H}_{2}+h v$

^ E-mail: thierry.stoecklin@u-bordeaux.fr followed by a dissociative recombination step with an electron:

$\mathrm{M}^{+}-\mathrm{H}_{2}+e^{-} \rightarrow \mathrm{MH}+\mathrm{H}$

In the present study, formation of $\mathrm{AlH}$ through this route is invetigated.

Association reactions containing metal ions can have a big impact on interstellar chemistry even if they do not produce a significant amount of molecules containing metals. This is due to the fact that most models of cloud chemical evolution assume very low abundances of metal ions since if higher abundances of metals ions were assumed this would also mean that the abundance of free electrons would be higher, which in turn would limit the chemical evolution of $\mathrm{H}, \mathrm{C}, \mathrm{N}, \mathrm{O}$, and $\mathrm{S}$ via ion/molecule reactions ((Mitchell 1978), Graedel et al. (1982)).

The recombination coefficients of atomic metal ions with an electron are typically $\sim 10^{-12} \mathrm{~cm}^{3} \mathrm{~s}^{-1}$ while for molecular metal ions they are $\sim 10^{-6} \mathrm{~cm}^{3} \mathrm{~s}^{-1}$ (Ip \& Axford 1986). In other words, the dissociative recombination described by equation 2 is much faster than radiative recombination (RR) of a metal ion in atomic form with an electron:

$\mathrm{M}^{+}+e^{-} \rightarrow \mathrm{M}+h v$

This means that having the metal ions in molecular rather than atomic form would lead to faster neutralization. This would in turn allow the model to include a higher abundance of metals (Petrie \& Dunbar (2000)).

Knowing the fractional abundance $f_{e}$ of electrons relative to $\mathrm{H}_{2}$ and the RR rate coefficient $k_{R R}^{e^{-}}$with electrons and following arguments of Smith et al. (1983) a minimum value of the RA rate 
coefficient $k_{R A}$ with $\mathrm{H}_{2}$ for which the RA process could compete with the RR process can be deduced:

$k_{R A}^{H_{2}} \geqslant k_{R R}^{e^{-}} \cdot f_{e}$

The RA rate constant for the formation of $\mathrm{Al}^{+}-\mathrm{H}_{2}$ has been previously calculated by Petrie \& Dunbar (2000) using transition state theory. For the temperatures 10,30 and $100 \mathrm{~K}$ they obtained the reaction rate constants $1.3 \cdot 10^{-23} \mathrm{~cm}^{3}$ molecule ${ }^{-1} \mathrm{~s}^{-1}, 8.6 \cdot 10^{-24}$ $\mathrm{cm}^{3}$ molecule $\mathrm{s}^{-1} \mathrm{~s}^{-1}$ and $4.5 \cdot 10^{-24} \mathrm{~cm}^{3}$ molecule ${ }^{-1} \mathrm{~s}^{-1}$ respectively. These relatively small values would exclude the formation of $\mathrm{AlH}$ through radiative association in molecular clouds.

Our previous study dedicated to the formation of $\mathrm{Na}^{+}-\mathrm{H}_{2}$ and $\mathrm{Na}^{+}-\mathrm{D}_{2}$ through RA showed that the transition state estimate of the RA rate coefficient was several orders of magnitude smaller than the value obtained using Close Coupling (CC) calculations. The CC reaction rate constant was also significantly closer to the experimental value. It is therefore the purpose of the present paper to check if $\mathrm{CC}$ calculations may provide large enough RA rates for the $\mathrm{Al}^{+}-\mathrm{H}_{2}$ and $\mathrm{Al}^{+}-\mathrm{D}_{2}$ systems to support the hypothesis of production of AlH and AlD in the gas phase through radiative association in molecular clouds.

Recent investigations of the $\mathrm{Al}^{+}-\mathrm{H}_{2}$ and $\mathrm{Al}^{+}-\mathrm{D}_{2}$ complexes were performed by Emmeluth et al. (2007). They performed experimental measurements and $a b$ initio calculations of the rotationally resolved rovibrational spectrum of these two complexes. Very good agreement between theory and experiment was obtained, which demonstrated the high accuracy of their potential energy surface (PES). In the present work we use their 3D PES and dipole moment surfaces to study the radiative association of these two complexes.

Numerous $\mathrm{CC}$ radiative association calculations have been performed on the formation of diatoms ( $\mathrm{HD}, \mathrm{HF}, \mathrm{OH}, \mathrm{NH}, \mathrm{CH}^{+} \mathrm{CF}^{+}$, $\mathrm{CN}, \mathrm{CO}, \mathrm{O}_{2}, \mathrm{AlCl}, \mathrm{NaCl}$...) see for example Szabo \& Gustafsson (2019); Andreazza et al. (2018); Öström et al. (2016); Stancil \& Dalgarno (1997) and the review by Nyman et al. (2015) and reference therein. In contrast, available calculations for triatomic systems are limited to the six systems: $\mathrm{H}_{2}^{+}-\mathrm{He}$ (Mrugala et al. 2003), $\mathrm{H}^{-}-\mathrm{H}_{2}$ (Ayouz et al. 2011), $\mathrm{H}^{-}-\mathrm{N}_{2}$ (Stoecklin et al. 2013), H-CO (Stoecklin et al. 2018b), $\mathrm{H}^{-}-\mathrm{CO}$ Stoecklin et al. (2018a) and $\mathrm{H}_{2}-\mathrm{Na}^{+}$ (Burdakova et al. 2019). The method developed in (Stoecklin et al. 2013) was used in the last three of the above mentioned works and is also applied in the current study.

The manuscript is organized as follows: In section 2 we briefly describe the main features of both the PES and the dipole moment surface calculated by Emmeluth et al. (2007) and we summarize the main steps of the method used to calculate the RA rate coefficients. In section 3 we present and discuss our results and their implication for the importance of the RA processes forming $\mathrm{Al}^{+}-\mathrm{H}_{2}$ and $\mathrm{Al}^{+}$$\mathrm{D}_{2}$ in the chemistry of molecular clouds. Conclusions are found in section 4 .

\section{METHODS}

As in our previous paper Burdakova et al. (2019), our calculations are performed using reactant Jacobi coordinates $(R, r, \theta)$ where $R$ is the intermolecular distance, $r$ the bond length of the diatom and $\theta$ the angle between $r$ and $R$.

\subsection{Potential energy surface and dipole moment}

We use the $a b$ initio potential energy surface (PES) and dipole moment surface (DMS) developed for this system by Emmeluth

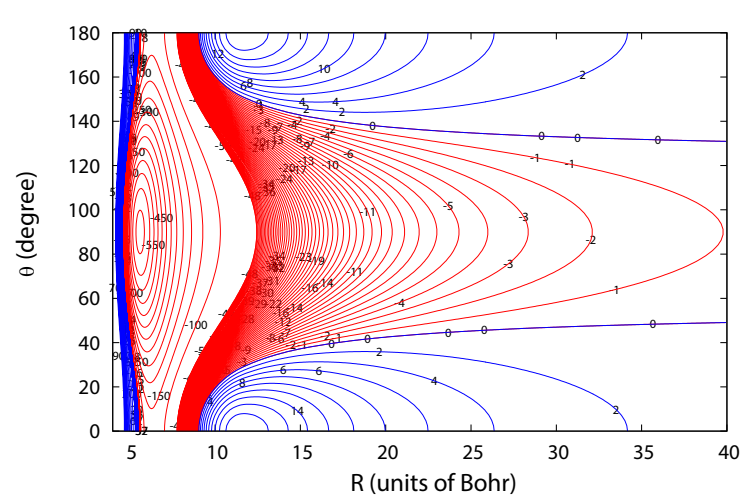

Figure 1. Contour plots of the potential energy surface of $\mathrm{Al}^{+}-\mathrm{H}_{2}$ obtained by Emmeluth et al. for $r=1.4097 a_{0}$. The energy is given in $\mathrm{cm}^{-1}$

et al. (2007). They are based on a grid of 400 points computed at the coupled cluster $\operatorname{CCSD}(\mathrm{T})$ level of theory and using the aug-ccpVQZ basis set and a set of $3 \mathrm{~s} 3 \mathrm{p} 2 \mathrm{~d} 2 \mathrm{f} 1 \mathrm{~g}$ bond functions located at the midpoint of the intermolecular axis. The ab initio grid includes $6 r$ grid points ranging from 1.0 to 2.2 bohr, 40 values of $R$ in the 2.75 to $40.0 \mathrm{bohr}$ interval and the four bond angles $0^{\circ}, 30^{\circ}, 60^{\circ}$ and $90^{\circ}$. Emmeluth et al. (2007) obtained an analytical model of the PES, depicted in Fig. 1, by fitting the ab initio grid, which describes accurately the short and long range expected asymptotic behaviours as well as the region of the well. The equilibrium geometry of the $\mathrm{Al}^{+} \mathrm{H}_{2}$ complex is found to be $\mathrm{T}$ shaped by the authors (Emmeluth et al. 2007) with $R=5.726$ bohr and an $\mathrm{H}_{2}$ bond distance of 1.4097 bohr, which is only 0.009 bohr larger than the bond length of a free $\mathrm{H}_{2}$ molecule. This latter result suggest that the use of the rigid rotor approximation could be appropriate for this system.

The minimum potential energy is $668.4 \mathrm{~cm}^{-1}$ below the reactants, while the binding energies of the $\mathrm{Al}^{+}-\mathrm{H}_{2}$ complex are 469.4 $\mathrm{cm}^{-1}$ and $506.4 \mathrm{~cm}^{-1}$ for the para and ortho species respectively.

\subsection{Bound states and Dynamics}

We use the method initially presented in Stoecklin et al. (2013) and there applied to formation of $\mathrm{N}_{2} \mathrm{H}^{-}$by RA. More details can be found in that paper. It is based on the driven equation formalism which connects the bound and scattering wave functions through the light-matter interaction operator.

The initial $\Psi_{i}^{J M}(R, r, \theta)$ and final $\Psi_{f}^{\alpha J^{\prime} M^{\prime}}(R, r, \theta)$ space fixed wave functions are written in the same set of Jacobi coordinates:

$\Psi_{i}^{J M}(R, r, \theta)=\frac{1}{R r} \sum_{v, j, l} \chi_{v, j, l}^{J M}(R) \varphi_{v j}(r) Y_{j l}^{J M}(\hat{R}, \hat{r})$

$\Psi_{f}^{\alpha J^{\prime} M^{\prime}}(R, r, \theta)=\frac{1}{R r} \sum_{v^{\prime}, j^{\prime}, l^{\prime}} \omega_{v^{\prime}, j^{\prime}, l^{\prime}}^{\alpha J^{\prime} M^{\prime}}(R) \varphi_{v^{\prime} j^{\prime}}(r) Y_{j^{\prime} l^{\prime}}^{J^{\prime} M^{\prime}}(\hat{R}, \hat{r})$

where $j, l$ and $J$ are respectively the quantum numbers associated with the rotational, orbital and total angular momenta of the system, while $\alpha$ denotes a given bound state. $\chi_{v, j, l}^{J M}(R)$ and $\omega_{v^{\prime}, j^{\prime}, l^{\prime}}^{\alpha J^{\prime} M^{\prime}}(R)$ are the $R$ dependent radial parts of the initial and final wave functions while $\varphi_{v j}(r)$ represents the $r$ dependent ro-vibrational parts. 


\section{Formation of Al containing molecular complexes in the gas phase in dense molecular clouds: Quantum study of the radi}

The wave functions are expanded in the same coupled angular basis sets:

$$
Y_{j l}^{J M}(\hat{r}, \hat{R})=\sum_{m_{j}, m_{l}}\left\langle j m_{j} l m_{l} \| J M\right\rangle y_{j}^{m_{j}}(\hat{r}) y_{l}^{m_{l}}(\hat{R})
$$

\subsubsection{Bound state calculations}

The bound states are calculated using 400 Chebyshev DVR grid points in the range [3-80] $\mathrm{a}_{0}$ for describing the radial part $R$ of the wave function. 18 Gauss-Hermite points in the range [0.725-2.09] $\mathrm{a}_{0}$ are used for the vibrational coordinate $r$, along with 10 rotational basis functions (Legendre polynomials) for each nuclear spin isomer of $\mathrm{H}_{2}$ and $\mathrm{D}_{2}$. Thus, $j$ ranges from 0 to 18 for para $\mathrm{H}_{2}$ and ortho $\mathrm{D}_{2}$, and from 1 to 19 for ortho $\mathrm{H}_{2}$ and para $\mathrm{D}_{2}$.

\subsubsection{Dynamics}

The radial part of the total wave function describing the system before and after radiative association is a solution of the following equation:

$$
\begin{array}{r}
{\left[\frac{d^{2}}{d R^{2}}-\frac{l(l+1)}{R^{2}}+k_{v j}^{2}(E)-U_{v j l}^{v^{\prime} j^{\prime} l^{\prime}}(R)\right] \chi_{v j l}^{v^{\prime} j^{\prime} l^{\prime}}(R)=} \\
\lambda_{v j l J M^{\prime} M^{\prime} M^{\prime}}^{\alpha(R)}
\end{array}
$$

where $U_{v j l}^{v^{\prime} j^{\prime} l^{\prime}}(R)$ are the matrix elements of the intermolecular potential, $k_{v j}$ are channel wave vectors and the right hand side of equation (8), $\lambda_{v j l J M}^{\alpha J^{\prime} M^{\prime}}(R)$, represent the driving terms, which are real and result from the dipolar couplings of the initial and scattering wave functions. Within the dipolar approximation.

$$
\begin{aligned}
\lambda_{v j l J M}^{\alpha J^{\prime} M^{\prime}}(R)= & -2 \mu_{\mathrm{Al}^{+}-\mathrm{H}_{2}} \int d \hat{R} d \hat{r} d r \varphi_{v j}(r) Y_{j l}^{J M}(\hat{r}, \hat{R}) \\
& \times \mu(\vec{R}, \vec{r}) \Psi_{f}^{\alpha, J^{\prime}, M^{\prime}}(R, r, \theta)
\end{aligned}
$$

For a charged atom interacting with a neutral homonuclear diatom, the dipole moment of the system can safely be assumed to lie along the intermolecular axis $R$. This aproximation was previously found to gives results in very good agreement with the ab initio dipole moments calculated for the $\mathrm{H}^{-}-\mathrm{N}_{2}$ Stoecklin et al. (2013) and $\mathrm{Na}^{+}-\mathrm{H}_{2}$ Burdakova et al. (2019) complexes. It is found to also perform well for $\mathrm{Al}^{+}-\mathrm{H}_{2}$ when compared with the ab initio dipole calculated by Emmeluth et al. (2007). The scattering wave function is propagated using the Magnus propagator from the classically forbidden region out to the asymptotic region where an incoming plane wave boundary condition is applied. The radiative association cross section for a given initial rovibrational state $(v, j)$ of $\mathrm{H}_{2}$ is then obtained from the following expression (corrected of a typo in Burdakova et al. (2019) ):

$\sigma_{v, j}(E)=\frac{8 \pi^{2}}{3 k_{v j}^{2} c^{3}} \sum_{J, J^{\prime}, \alpha} \omega_{\alpha}^{3}\left[M_{v, j, J^{\prime}}^{\alpha, J^{\prime}}(E)\right]^{2}$

where $\omega_{\alpha}$ is the angular frequency of the emitted photon and $M_{v, j, J^{\prime}}^{\alpha, J^{\prime}}(E)$ are obtained by integrating state-selected driving terms $\lambda_{v j l J M}^{\alpha J^{\prime} M^{\prime}}(R)$ over $R$ and summing over the indices $M, l$ and $M^{\prime}$.

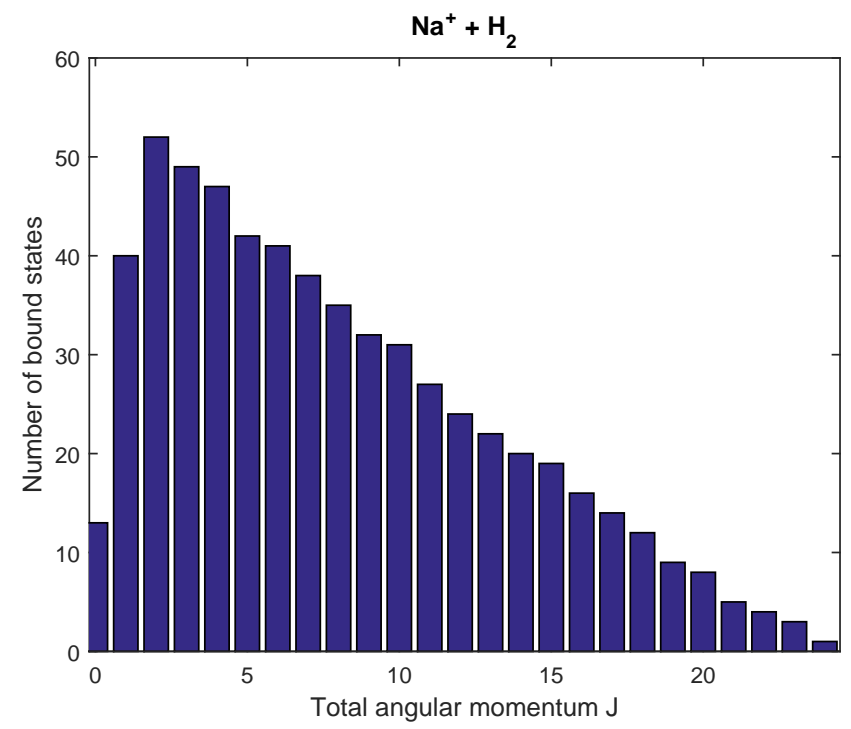

Figure 2. Number of bound states of $\mathrm{Al}^{+}-\mathrm{H}_{2}$ as a function of the total angular momentum quantum nnumber of the system.

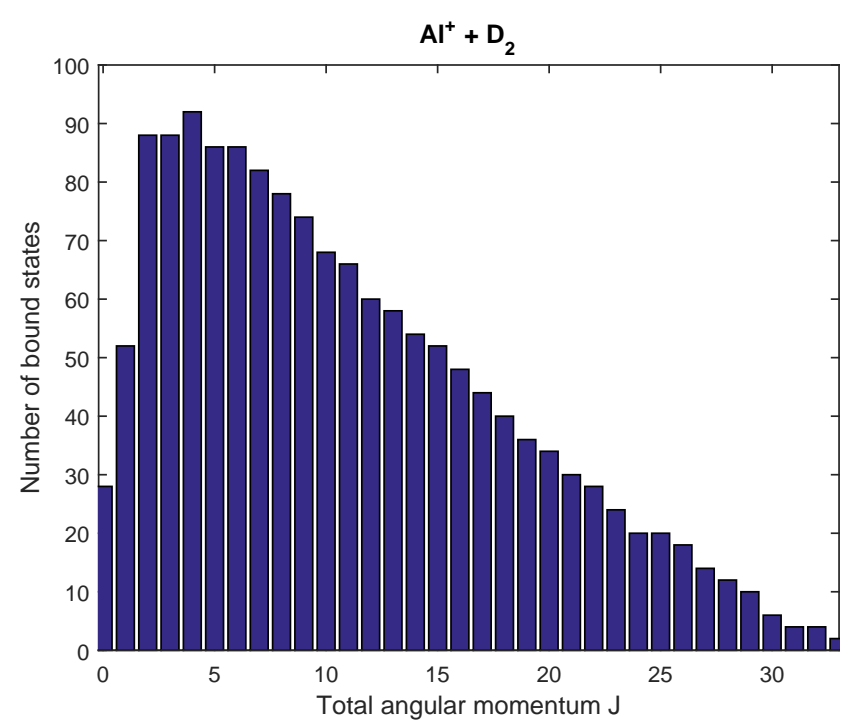

Figure 3. Number of bound states of $\mathrm{Al}^{+}-\mathrm{D}_{2}$ as a function of the total angular momentum quantum number of the system.

\section{RESULTS}

Similarly to previous studies the para and ortho spin isomers of $\mathrm{H}_{2}$ and $\mathrm{D}_{2}$ were treated separately. States lying above the zero point energy level of the reactants but with no open rotational predissociation channels are treated as bound states. This results in 311 para and 293 ortho bound states needing to be included in the $\mathrm{Al}^{+}-\mathrm{H}_{2}$ $\mathrm{RA}$ calculations. For $\mathrm{Al}^{+}-\mathrm{D}_{2} \mathrm{RA}$ calculations these numbers are more than doubled with 753 para and 721 ortho bound states.

Figs. 2 and 3 show respectively the variation of the calculated number of bound states of $\mathrm{Al}^{+}-\mathrm{H}_{2}$ and $\mathrm{Al}^{+}-\mathrm{D}_{2}$ as a function of the total angular momentum quantum number $J$. The total number of bound states is 604 for $\mathrm{Al}^{+}-\mathrm{H}_{2}$ and 1474 for $\mathrm{Al}^{+}-\mathrm{D}_{2}$ while the 


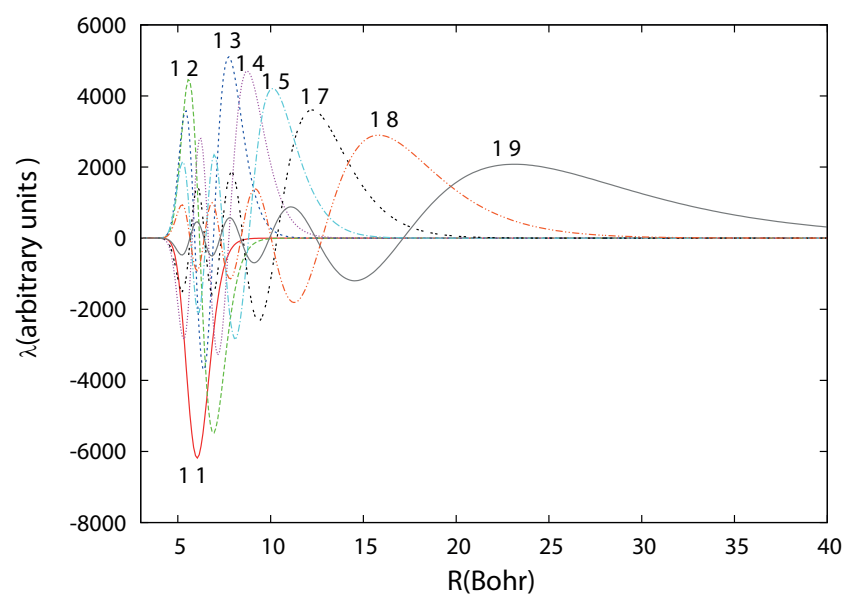

Figure 4. Variation of the $l=0$ component of the $J=0$ driving terms $\left(\lambda_{v=0, j=0, l=0, J=0}^{\alpha, J^{\prime}=1}(R)\right)$ as a function of the intermolecular coordinate for a collision energy of $1 \mathrm{~cm}^{-1}$. The two numbers reported on each curve are the quantum numbers $J^{\prime}$ and $\alpha$ of the final bound state.

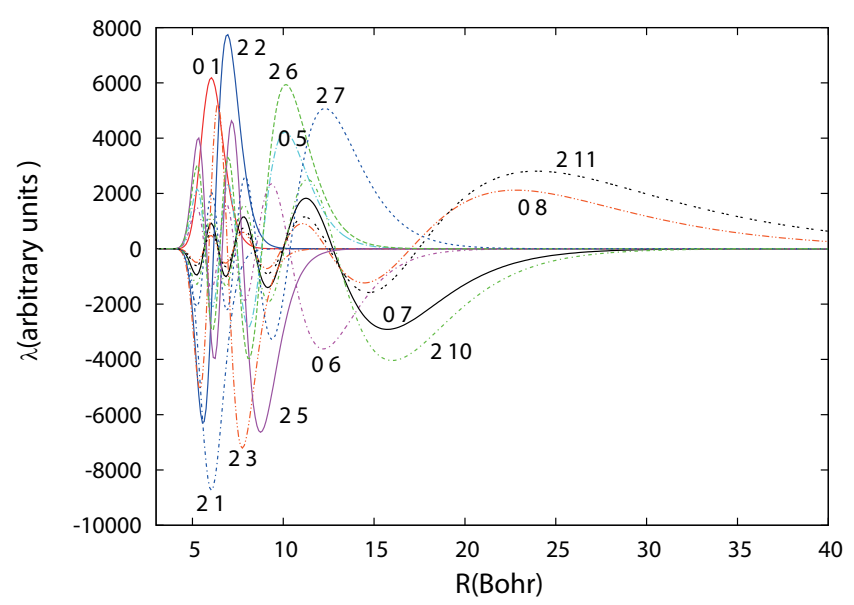

Figure 5. Variation of the $l=2$ component of the $(J=1, \epsilon=-)$ driving terms $\left(\lambda_{v=0, j=2, l=2, J=1}^{\alpha, J^{\prime}}(R)\right)$ as a function of the intermolecular coordinate for a collision energy of $1 \mathrm{~cm}^{-1}$. The two numbers reported on each curve are the quantum numbers $J^{\prime}$ and $\alpha$ of the final bound state.

largest value of $J$ resulting in a bound state is 24 for the $\mathrm{Al}^{+}-\mathrm{H}_{2}$ and 33 for $\mathrm{Al}^{+}-\mathrm{D}_{2}$.

Figs. 4 and 5 illustrates the variation of the driving term $\lambda_{v=0 j l J}^{\alpha J^{\prime} M^{\prime}}(R)$ as a function of the intermolecular distance respectively for $(J=0, \varepsilon=+)$ and $(J=1, \varepsilon=-)$ at a collision energy of 1 $\mathrm{cm}^{-1}$. Clearly, the lower bound states which are localized in a narrower intermolecular distance interval give a localized driving term while the most excited bound states extend over a large intermolecular range and give rise to an extended domain of the driving term. The present $\mathrm{Al}^{+}-\mathrm{D}_{2}$ driving terms are also seen to be localized in a narrower intermolecular distance interval than those of the $\mathrm{Na}^{+}$$\mathrm{H}_{2}$ system (Burdakova et al. 2019). As the cross section is directly proportional to the square of the integral of the contributing driving terms $(\lambda)$ at a given collision energy, this will have impact on the cross sections.

The variation as a function of collision energy of the $\mathrm{Al}^{+}-\mathrm{H}_{2}$

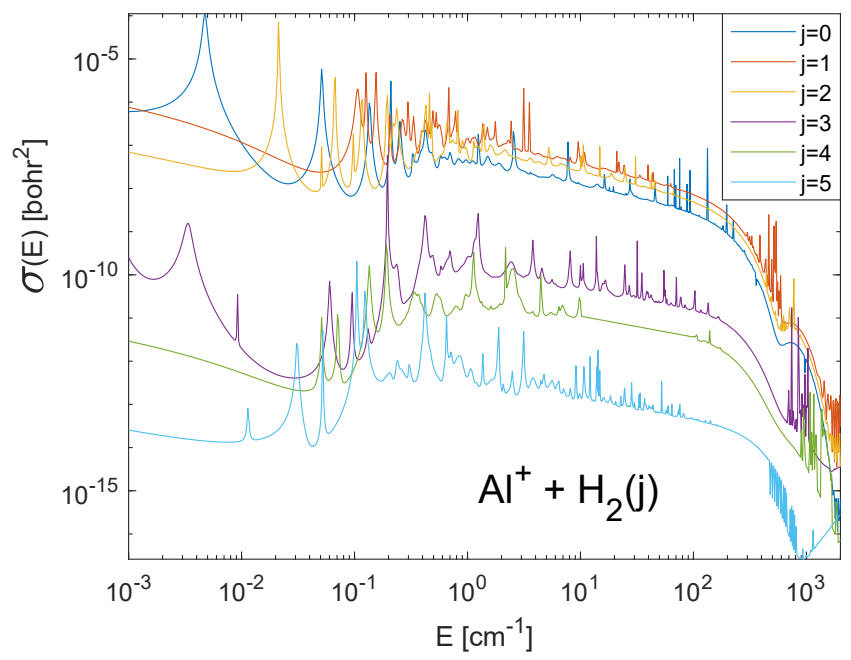

Figure 6. Radiative association cross section of $\mathrm{Al}^{+}-\mathrm{H}_{2}$ as a function of collision energy depicted for different values of $j$.

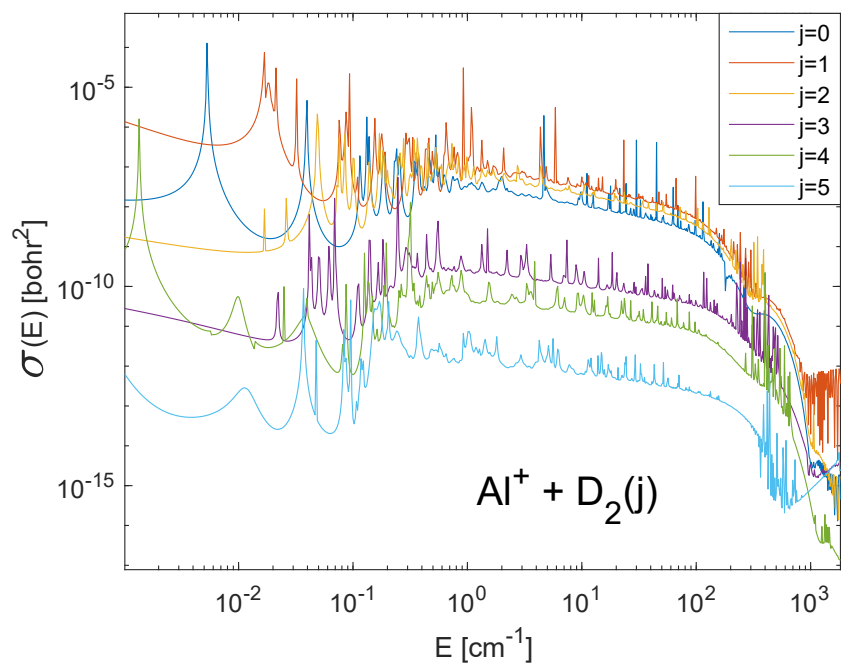

Figure 7. Radiative association cross section of $\mathrm{Al}^{+}-\mathrm{D}_{2}$ as a function of collision energy depicted for different values of $j$.

and $\mathrm{Al}^{+}-\mathrm{D}_{2}$ RA cross sections is presented in figures 6 and 7 for various initial rotational states of the diatomic fragments. These figures are very similar to those obtained previously for the $\mathrm{Na}^{+}-\mathrm{H}_{2}$ and $\mathrm{Na}^{+}-\mathrm{D}_{2}$ systems (Burdakova et al. 2019) while the magnitude of the cross sections involving $\mathrm{Al}^{+}$are smaller. This can be understood by comparing the PES and the bound states of these sytems. The $\mathrm{Na}^{+}-\mathrm{H}_{2}$ PES is deeper than the one of $\mathrm{Al}^{+}-\mathrm{H}_{2}$. As a result, the number of bound states of $\mathrm{Al}^{+}-\mathrm{H}_{2}$ is smaller. The lowest bound state energies are also quite different $\left(-844.37 \mathrm{~cm}^{-1}\right)$ for $\mathrm{Na}^{+}-\mathrm{H}_{2}$ and $\left(-461.81 \mathrm{~cm}^{-1}\right)$ for $\mathrm{Al}^{+}-\mathrm{H}_{2}$. We note that the cross section is proportional to $\omega^{3}$.

The mentioned features reduce the $\mathrm{Al}^{+}-\mathrm{H}_{2} / \mathrm{D}_{2}$ RA cross sections compared to those of $\mathrm{Na}^{+}-\mathrm{H}_{2} / \mathrm{D}_{2}$ by about two orders of magnitude. We also notice that the initial rotational state $j=1$ gives the largest $\mathrm{Al}^{+}-\mathrm{H}_{2} / \mathrm{D}_{2} \mathrm{RA}$ cross sections while it is the initial rotational state $j=2$ for the $\mathrm{Na}^{+}-\mathrm{H}_{2} / \mathrm{D}_{2} \mathrm{RA}$ cross sections.

$j$-resolved RA rate coefficients are presented in Figs. $8\left(\mathrm{Al}^{+}{ }_{-}\right.$ 
Formation of Al containing molecular complexes in the gas phase in dense molecular clouds: Quantum study of the radi

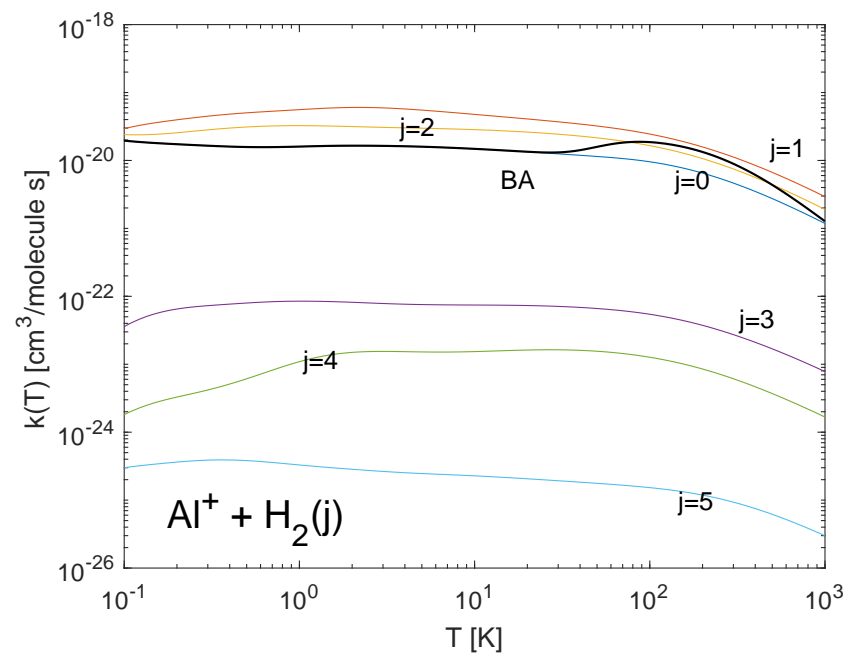

Figure 8. Radiative association rate coefficient for forming $\mathrm{Al}^{+}-\mathrm{H}_{2}$ as a function of temperature depicted for different values of $j$.

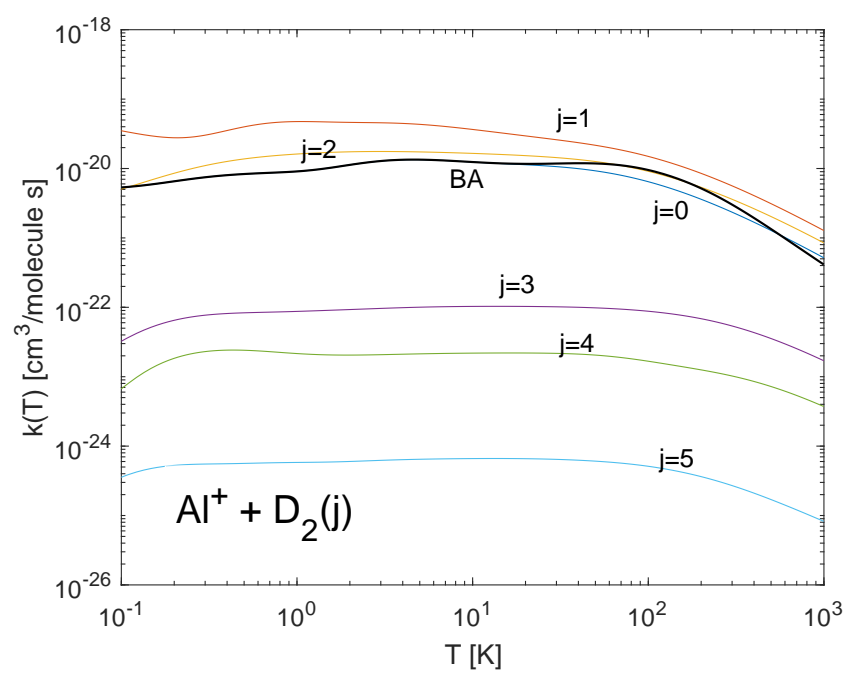

Figure 9. Radiative association rate coefficient for forming $\mathrm{Al}^{+}-\mathrm{D}_{2}$ as a function of temperature depicted for different values of $j$.

$\left.\mathrm{H}_{2}\right)$ and $9\left(\mathrm{Al}^{+}-\mathrm{D}_{2}\right)$. In both figures the total Boltzmann averaged reaction rate constants are also reported. A ratio of 2:1, obtained from the spin statistics was included when combining the ortho- $\mathrm{D}_{2}$ and para- $\mathrm{D}_{2}$ rate coefficients while a ratio of $3: 1$ was used when combining the ortho- $\mathrm{H}_{2}$ and para- $\mathrm{H}_{2}$ rate coefficients.

For both reactions the Boltzmann averaged rate coefficients are seen to be almost flat at low temperature before reaching a maximum close to $87 \mathrm{~K}$ for $\mathrm{Al}^{+}-\mathrm{H}_{2}$ formation while two less marked maxima are visible at 5 and $43 \mathrm{~K}$ for the $\mathrm{Al}^{+}-\mathrm{D}_{2}$ formation. Both rate coefficients thereafter decrease monotonously and follow the expected $T^{-1}$ law predicted by modified thermal theory. This general behaviour was also obtained and analysed for similar ionic complexes like $\mathrm{N}_{2}-\mathrm{H}^{-}$Stoecklin et al. (2013) and $\mathrm{Na}^{+}-\mathrm{H}_{2}$ Burdakova et al. (2019).

Above $10 \mathrm{~K}$, the largest $\mathrm{Al}^{+}-\mathrm{H}_{2} \mathrm{RA}$ rate constant is $1.9 \cdot 10^{-20} \mathrm{~cm}^{3}$ molecule ${ }^{-1} \mathrm{~s}^{-1}$ at $T=87$ while it is $1.2 \cdot 10^{-20}$ $\mathrm{cm}^{3}$ molecule $\mathrm{s}^{-1}$ at $43 \mathrm{~K}$ in the case of the $\mathrm{Al}^{+}-\mathrm{D}_{2} \mathrm{RA}$. For form-

\begin{tabular}{lll}
\hline \hline Temperature $(\mathrm{K})$ & $r(T)$ Pietrie et al. & $r(T)$ current study \\
\hline 10 & $1.3 \cdot 10^{-23}$ & $1.5 \cdot 10^{-20}$ \\
30 & $8.6 \cdot 10^{-24}$ & $1.3 \cdot 10^{-20}$ \\
100 & $4.5 \cdot 10^{-24}$ & $1.9 \cdot 10^{-20}$ \\
\hline
\end{tabular}

Table 1. Comparison between the CC RA rate coefficients obtained in the current study with the ones calculated by Petrie and Dunbar using transition state theory. The rate coefficients are given in $\mathrm{cm}^{3}$ molecule $\mathrm{e}^{-1} \mathrm{~s}^{-1}$

\begin{tabular}{llll}
\hline$T(\mathrm{~K})$ & $k_{R A}$ & $k_{R R}$ & $f_{e}^{\max }$ \\
\hline \hline 10 & $1.5 \cdot 10^{-20}$ & $2.8 \cdot 10^{-11}$ & $5.4 \cdot 10^{-10}$ \\
100 & $1.9 \cdot 10^{-20}$ & $5.8 \cdot 10^{-12}$ & $3.3 \cdot 10^{-9}$ \\
\hline
\end{tabular}

Table 2. Maximum electron fractional abundance $f_{e}^{\text {max }}$ relative to $\mathrm{H}_{2}$ for which the radiative association to form $\mathrm{Al}^{+}-\mathrm{H}_{2}$ would be more efficient than radiative recombination of $\mathrm{Al}^{+}$with an electron for two temperatures. The RA and RR rate coefficients are given in $\mathrm{cm}^{3}$ molecule $\mathrm{e}^{-1} \mathrm{~s}^{-1}$

ing the $\mathrm{Na}^{+}-\mathrm{H}_{2}$ and $\mathrm{Na}^{+}-\mathrm{D}_{2}$ complexes we obtained maximum values of about $5 \cdot 10^{-18} \mathrm{~cm}^{3}$ molecule $\mathrm{s}^{-1}$ at $T=200 \mathrm{~K}$ and $7 \cdot 10^{-20} \mathrm{~cm}^{3}$ molecule ${ }^{-1} \mathrm{~s}^{-1}$ at $100 \mathrm{~K}$. There is thus a big difference in the isotope effect for the $\mathrm{Al}^{+}-\mathrm{D}_{2} / \mathrm{Al}^{+}-\mathrm{H}_{2}$ systems and the $\mathrm{Na}^{+}-\mathrm{D}_{2} / \mathrm{Na}^{+}-\mathrm{H}_{2}$ systems. The $\mathrm{Na}^{+}-\mathrm{D}_{2} / \mathrm{Na}^{+}-\mathrm{H}_{2}$ systems show a strong isotope effect while the maximum RA rate coefficient for forming the $\mathrm{Al}^{+}-\mathrm{D}_{2}$ complex is much closer to the one for forming the $\mathrm{Al}^{+}-\mathrm{H}_{2}$ complex.

The reaction rate constants for formation of the $\mathrm{Al}^{+}-\mathrm{H}_{2}$ molecule have been previously calculated by Petrie \& Dunbar (2000) based on transition state theory. A comparison between their results and ours is presented in Table 1 . At $10 \mathrm{~K}$ our CC rate coefficient is seen to be three orders of magnitude larger than the one of Petrie \& Dunbar (2000), while at $100 \mathrm{~K}$ our value is almost four orders of magnitude larger than theirs. This difference is however not large enough to question their conclusion that RA forming $\mathrm{Al}^{+}-\mathrm{H}_{2}$ is too slow to matter in astrochemistry.

We can indeed evaluate the maximum fractional abundance of electrons $f_{e}^{\max }$ which makes RA important for the chemistry of an interstellar cloud, using equation (4). For this purpose, we need to know the RR rate of $\mathrm{Al}^{+}$with an electron, which unfortunately is not available. However, as RR rates depend only weakly on the nature of the positive ion (Biondi (1969) we can use the expression given by Prasad \& Huntress (1980) for $\mathrm{Na}^{+}$, $k_{R R}^{e-}(T)=2.7 \cdot 10^{-12}(T / 300)^{-0.69} \mathrm{~cm}^{3} \mathrm{~s}^{-1}$. The maximum fractional abundance of electrons $f_{e}^{\max }$ for which the RA rate for forming $\mathrm{Al}^{+}-\mathrm{H}_{2}$ would be more efficient than $\mathrm{RR}$ of $\mathrm{Al}^{+}$with an electron $f_{e}^{\max }$ is reported in Table 2 for $10 \mathrm{~K}$ and $100 \mathrm{~K}$. These values of $f_{e}^{\text {max }}$ appear to be an order of magnitude smaller than the usual estimate of the fractional abundance of electrons relative to $\mathrm{H}_{2}$ in dense molecular clouds.

We conclude, following the arguments used by Smith et al. (1983) leading to equation (4) that the $\mathrm{Al}^{+}-\mathrm{H}_{2} \mathrm{RA}$ rate coefficients are not large enough for this mode of production of $\mathrm{AlH}$ in the gas phase to need to be included in the chemistry models of dense molecular clouds. 


\section{CONCLUSION}

The formation of $\mathrm{Al}^{+}-\mathrm{H}_{2}$ and $\mathrm{Al}^{+}-\mathrm{D}_{2}$ through $\mathrm{RA}$ was investigated theoretically at the close-coupling level using a recent 3D PES and dipole moment surface. The total number of bound states obtained for the $\mathrm{Al}^{+}-\mathrm{D}_{2}$ molecule is more than twice as large as for the $\mathrm{Al}^{+}-\mathrm{H}_{2}$ molecule. This is due to the mass difference between the two systems. This also affects the largest value of $J$ resulting in a bound state. For the $\mathrm{Al}^{+}-\mathrm{H}_{2}$ molecule the largest value of $J$ is 24 while it is 33 for the $\mathrm{Al}^{+}-\mathrm{D}_{2}$ molecule.

The $\mathrm{Na}^{+}-\mathrm{H} /-\mathrm{D}_{2}$ system which we recently investigated (Burdakova et al. 2019) was found to exhibit a very strong istope effect, while the RA rate constants of $\mathrm{Al}^{+}-\mathrm{D}_{2}$ and $\mathrm{Al}^{+}-\mathrm{H}_{2}$ are of the same magnitudes. The $\mathrm{Al}^{+}-\mathrm{H}_{2} / \mathrm{D}_{2} \mathrm{RA}$ rate coeffcients are furthermore found to be two orders of magnitude smaller than those of $\mathrm{Na}^{+}-\mathrm{H}_{2} / \mathrm{D}_{2}$ as a result of a globally less attractive potential

Our rate coefficient for forming $\mathrm{Al}^{+}-\mathrm{H}_{2}$ at $100 \mathrm{~K}$ is almost four orders of magnitude larger than the available transition state estimate of Petrie \& Dunbar (2000). However, following the arguments used by Smith et al. (1983), we confirm that the $\mathrm{Al}^{+}-\mathrm{H}_{2} \mathrm{RA}$ rate coefficients are not large enough for this mode of production of $\mathrm{AlH}$ in the gas phase to need to be included in chemistry models of dense molecular clouds.

\section{ACKNOWLEDGMENTS}

We gratefully acknowledge support from the Swedish Research Council (grant number 2016-03275). The calculations were performed at the Mesocentre de Calcul Intensif Aquitain computing facilities of the Universit de Pau et des Pays de l'Adour.

\section{DATA AVAILABILITY}

The data underlying this article are available in the article.

\section{REFERENCES}

Andreazza C. M., Almeida A. A., Vichietti R. M., 2018, MNRAS, 477, 548 Ayouz M., Lopes R., Raoult M., Dulieu O., Kokoouline V., 2011, Phys. Rev. A, 83, 052712

Biondi M. A., 1969, Can. J. Chem., 43, 1711

Burdakova D., Nyman G., Stoecklin T., 2019, Monthly Notices of the Royal Astronomical Society, 485, 5874

Cernicharo J., Guelin M., 1987, Astron. Astrophys., 183, L10

Emmeluth C., Poad B. L. J., Thompson C. D., Weddle G., Bieske E. J., Buchachenko A. A., Grinev T. A., Klos J., 2007, J. Chem. Phys., 127, 164310

Graedel T. E., Langer W. D., Frerking M. A., 1982, Ap. J. S., 48, 321

Ip W. H., Axford W. I., 1986, Nature, 321, 682

Kamínski, T. et al., 2016, A\&A, 592, A42

Kawaguchi K., Kagi E., Hirano T., Takano S., Saito S., 1993, Astrophys. J., 406, L39

Kirby K., Dalgarno A., 1978, Astrophys. J., 224, 444

Mitchell G. F., 1978, A. J., 83, 1612

Mrugala F., Spirko V., Kraemer W. P., 2003, J. Chem. Phys., 118, 10547

Nyman G., Gustafsson M., Antipov S. V., 2015, Int. Rev. Phys. Chem., 34, 385

Öström J., Bezrukov D. S., Nyman G., Gustafsson M., 2016, J. Chem. Phys., 114,249901

Petrie S., Dunbar R. C., 2000, J. Phys. Chem. A, 104, 4480

Prasad S. S., Huntress J. W. T., 1980, ApJS, 43, 1

Smith D., Adams G., Alge E., Herbst E., 1983, Apj, 272, 365
Stancil P. C., Dalgarno A., 1997, Ap. J., 490, 76

Stoecklin T., Lique F., Hochlaf M., 2013, Phys. Chem. Chem. Phys., 15, 13818

Stoecklin T., Halvick P., Lara-Moreno M. d. J., Trabelsi T., Hochlaf M., 2018a, Faraday Discuss., p. 101

Stoecklin T., Halvick P., Yu H.-G., Nyman G., Ellinger Y., 2018b, Monthly Notices of the Royal Astronomical Society, 475, 2545

Szabo P., Gustafsson M., 2019, MNRAS, 483, 3574

Tenenbaum E. D., Dodd J. L., Milam S. N., Woolf N. J., Ziurys L. M., 2010, The Astrophysical Journal Supplement Series, 190, 348

Turner B. E., Steimle T. C., Meerts L., 1994, Astrophys. J., 426, L97

Ziurys L. M., Apponi A. J., Phillips T. G., 1994, Astrophys. J., 433, 729

Ziurys L. M., Apponi A. J., Gue'lin M., Cernicharo 1995, J. Astrophys., 445, L47

This paper has been typeset from a $\mathrm{T}_{\mathrm{E}} \mathrm{X} / \mathrm{LAT}_{\mathrm{E}} \mathrm{X}$ file prepared by the author. 